\title{
Correction to: Surgical Outcomes and Comparative Analysis of Transduodenal Ampullectomy and Pancreaticoduodenectomy: A Single-Center Study
}

Eun-Ki Min, MD¹, Seung Soo Hong, MD ${ }^{1}$, Ji Su Kim, MD¹, Munseok Choi, $\mathrm{MD}^{2}$, Hyeo Seong Hwang, $\mathrm{MD}^{3}$, Chang Moo Kang, MD, PhD ${ }^{1}$, Woo Jung Lee, MD, PhD $^{1}$, Dong Sup Yoon, MD, PhD ${ }^{1}$, and

Ho Kyoung Hwang, MD, PhD ${ }^{1}$

${ }^{1}$ Division of Hepatobiliary and Pancreatic Surgery, Department of Surgery, Severance Hospital, Yonsei University College of Medicine, Seodaemun-gu, Seoul, South Korea; ${ }^{2}$ Department of Surgery, Yongin Severance Hospital, Yonsei University College of Medicine, Seoul, South Korea; ${ }^{3}$ Department of Surgery, National Health Insurance Service Ilsan Hospital, Ilsan, South Korea

\section{CORRECTION TO:}

ANN SURG ONCOL

HTTPS://DOI.ORG/10.1245/S10434-021-11190-9

The spelling of Yonsei University College of Medicine in affiliation number 1 was corrected in the original article.
Publisher's Note Springer Nature remains neutral with regard to jurisdictional claims in published maps and institutional affiliations.

The original article can be found online at https://doi.org/10.1245/ s10434-021-11190-9.

(C) The Author(s) 2022

Published Online: 15 February 2022

H. K. Hwang, MD, PhD

e-mail:drhhk@yuhs.ac 